\title{
Assessing the Dynamic Relationship Between Small and Large Cap Stock Prices
}

\author{
K.Y. Ho ${ }^{a}$, B.D. Ernst ${ }^{b}$ and Z.Y. Zhang ${ }^{c}$ \\ ${ }^{a}$ College of Business and Economics, Australian National University, Australia \\ ${ }^{b}$ Accretive Health, Chicago, IL 60611 USA \\ ${ }^{c}$ School of Accounting, Finance \& Economics, Edith Cowan University, Australia \\ Email: zhaoyong.zhang@ecu.edu.au
}

\begin{abstract}
The historical long-run return on small capitalization stocks has unquestionably outperformed large capitalization stocks since 1926. The phenomenon of small capitalization stocks having higher riskadjusted returns compared with large capitalization stocks is an equity market anomaly first discovered in 1981. Since then, many academics and investors have strongly argued that "size is dead".

This paper argues that far from being dead, the phenomenon of size effect appears alive and well and it could be exploited effectively over long-term investment horizons. To analyze this phenomenon, we focus specifically on the dynamics of small cap and large cap prices. We test for multivariate cointegration among the small cap and large cap stock prices and other major macroeconomic factors from 1980 to 2006. After conducting robustness tests on forward recursive and ten year rolling samples, we find evidence of one longrun cointegrating vector. Of more importance, there is a consistently negative and highly significant relationship between small and large cap stock prices. This could suggest that the size effect exhibits a cyclical pattern. Our analysis also provides supporting evidence that the size effect appears to exhibit predictable reversals when considering long investment horizons. Furthermore, we demonstrate how small cap stocks can be viewed as less risky than large cap stocks over long holding periods. Finally, we make suggestions on how asset managers and individual investors can enhance returns based on our overall results.
\end{abstract}

Keywords: small and large capitalization stocks, cap prices, multivariate cointegration, size effect 


\section{INTRODUCTION}

The historical long-run return on small capitalization stocks has unquestionably outperformed large capitalization stocks since 1926. According to the Dow Theory Forecasts, if the stocks listed on the New York Stock Exchange (NYSE), American Stock Exchange (AMEX), and Nasdaq are split into deciles by market capitalization, the tenth decile consisting of the smallest of micro cap stocks has realized an average annualized return of $14.0 \%$ from 1926 to 2006 versus an annualized return of $9.6 \%$ for the first decile consisting of the largest of large caps. The excess return of small capitalization stocks was first discovered by Banz (1981) who reveals that the rate of a stock's annualized return increases as a firm's market capitalization decreases from large cap to mid cap to small cap to micro cap, suggesting a firm's size is a strong determinant of a stock's return. Banz also discovered that small cap stocks still produce abnormally high returns even after adjusting for risk in the capital asset pricing model (CAPM). However, it is important to note that even though small caps tend to outperform large caps in the long-run, large caps tend to outperform small caps more often when looking at monthly periods. The strong tendency of small caps to yield higher returns than large caps over long holding periods has important investment implications for portfolio managers. Gustafson and Miller (1999) suggest small cap stock data is not random, but exhibits persistent serial autocorrelation. In other words, a pattern exists where a year of strong small cap performance tends to follow a year of strong small cap performance. For example, the years 1975-1983 exemplify a very strong serial autocorrelative relationship. Each year in the period witnessed strong small cap outperformance, an unusually long cycle compared to other cycles.

A study by Fama and French (1988) suggests that, in general, long-run stock price behavior is predictable. Empirical evidence from their research supports negative autocorrelations in long-run stock returns. Reinganum (1992) extended the findings of Fama and French (1988) by applying the same question of cyclicality to the "size effect." He defines the "size effect" as the difference between the performance of the bottom decile of smallest firms and the top decile of largest firms listed on the NYSE. Using monthly stock data from 1926 to 1989, he finds that investment horizons of five years exhibit highly significant negative serial autocorrelation. Thus, a five-year period in which large caps outperform small caps is typically followed by a five-year period in which small caps outperform large caps and vice versa.

Most of the existing studies, including Fama and French (1992), Daniel and Titman (1997), and Dichev (1998), employ a simple OLS regression analysis to explain the size effect as insufficient liquidity, transaction costs, different measures of risk, or investor behavior, using stock returns or the difference in stock returns as defined by Reinganum (1992). Virtually no studies investigate relationships between small and large cap stock prices. Based on the findings of Fama and French (1988) and Reinganum (1992, 1999), which respectively suggest that the size effect and stock prices behave cyclically, the potential for such a long-run relationship between small and large cap stock prices exists, but no studies yet to examine it. Using UK stock market data from 1955 to 2000, Kanas and Kouretas (2005) find evidence of cointegration between the current price of small cap stock portfolios and the lagged price of large cap stock portfolios. They argue that large firm portfolio prices are "long-run forcing variables" for small firm portfolio prices, suggesting that market capitalization is a driving force of the lead-lag effect in the long-run. There is a positive relationship between the current price of small cap stock portfolios and the lagged price of large cap stock portfolios. Using data from the Warsaw Stock Exchange, Gebka (2003) also finds empirical evidence supporting the idea that small cap stock portfolios are slower to adjust to market-wide information than large cap stock portfolios.

According to theory, small and large cap stocks may drift apart from each other in the short-run, but they should not diverge substantially from one another in the long-run. After all, if the system is to return to longrun equilibrium, the movements of at least some variables must respond to the magnitude of the disequilibrium. Consequently, if the two stock price series are cointegrated, a vector error correction model seems to be the most appropriate for determining any long-run relationships that may exist. The purpose of this study is to investigate the long-run relationship between small and large cap stock prices by employing a vector error correction model framework with US stock market data from 1980 to 2006 . We prostitute that a negative relationship between small cap stock prices and large cap stock prices exists in the long-run. If a long-run relationship exists, the cyclical nature of the size effect can be at least partially explained by the tendency of small and large cap stock returns to force each other towards a general long-run equilibrium level. Therefore, when shocks occur in the short-run that temporarily force small and large cap prices out of their long-run equilibrium level, the potential exists for prudent investors to capitalize on the short-run mispricing to enhance long-run returns. The results of this study have important implications for academics, 
asset managers, and even individual investors who desire to identify and implement profitable portfolio strategies for the long-run.

The rest of this paper is organized as follows. Section 2 presents the methodology employed in this study. Section 3 discusses the data and descriptive statistics, and presents the empirical results. Section 4 concludes.

\section{METHODOLOGY AND THE MODEL}

To investigate the relationship explained in Section 1, the vector autoregressive (VAR) process provides a good framework for working with stock prices and macroeconomic time-series data. The VAR model is flexible, easy to estimate, and usually yields a good fit to macroeconomic data. Of more importance, the VAR allows the possibility of combining long-run and short-run information in the data by exploiting the cointegration property. Consequently, the VAR can give additional insight into the problem compared to theory-based ordinary least squares regression models.

Engle and Granger (1987) maintain that a linear combination of two or more nonstationary series may be stationary. If such a stationary linear combination exists, the nonstationary time series are cointegrated, establishing the existence of a long-run relationship among the variables. However, the Engle-Granger (EG) two-step procedure only estimates one cointegrating vector, and also treats a specific variable as endogenous. The Johansen $(1991,1995)$ methodology can estimate more than one cointegrating vector and simultaneously estimates the short-run and long-run cointegrating relationships, making the interpretation more intuitive since the coefficients can be naturally classified as short-run or long-run effects. To provide robustness to the overall sample results and awareness to any time variation in the long-run relationships, we conduct the Johansen test and estimate the cointegrating vector over the full sample, forward recursive samples, and ten year rolling samples. The tests will provide insight into the credibility of the full sample results, eliminating any concern that an accidental long-run relationship was estimated. The test will also reveal the degree of parameter stability across the sample period, which can potentially highlight sub-periods where other factors are at play. The forward recursive samples can highlight any changes that occur as time progresses forward from 1980. The ten year rolling samples can provide insight into the degree of parameter volatility by providing estimations for several different snapshots in time. Since the study period is 1980-2006, only a portion of the entire available CRSP dataset, these tests can eliminate any concern about data mining.

Since we are working with multiple variables, the $m$-variable case is presented for the $k^{\text {th }}$ order VAR. A general version of the model can be written as:

$$
Y_{t}=\mu+\Pi_{1} Y_{t-1}+\ldots+\Pi_{\mathrm{k}} Y_{t-k}+\varepsilon_{t}
$$

where $Y_{t}$ is a $(m \times 1)$ random vector of time series variables $\left(Y_{1 t}, Y_{2 t}, \ldots, Y_{m t}\right)^{\prime}$ with order of integration less than or equal to one, $\mu$ is a ( $m \times 1)$ vector of constants, $\Pi_{i}$ is a $(m \times m)$ matrix of parameters, and $\varepsilon_{t}$ is a $(m \times 1)$ vector $\left(\varepsilon_{1 t}, \varepsilon_{2 t}, \ldots, \varepsilon_{m t}\right)^{\prime}$ of white noise terms.

Next, we subtract $Y_{t-1}$ from both sides of equation (1) and rearrange the terms. If we let $\Pi=\left(\Pi_{\mathrm{k}}+\Pi_{\mathrm{k}}+\ldots+\right.$ $\left.\Pi_{\mathrm{k}}-I\right)$ and $\Gamma_{i}=-\left(\Pi_{\mathrm{i}+1}+\Pi_{\mathrm{i}+2}+\ldots+\Pi_{k}\right)$, we can substitute these into equation (1). We can now write the $k^{\text {th }}$ order VAR model in vector error correction model (VECM) form:

$$
\Delta Y_{t}=\mu+\sum_{i=1}^{k-1} \Gamma_{i} \Delta Y_{t-1}+\Pi Y_{i-k}+\varepsilon_{t}
$$

where $\Delta$ is the first difference, $Y_{t}$ is a $(m \times 1)$ random vector of time series variables with order of integration less than or equal to one, $\mu$ is a $(m \times 1)$ vector of constants, $\Gamma_{i}$ are $(m \times m)$ matrices of parameters, $\varepsilon_{t}$ is a sequence of zero-mean $m$-dimensional white noise vectors, and $\Pi$ is a $(m \times m)$ matrix of parameters where the rank determines the number of long-run cointegrating vectors between the variables.

The VECM represented by equation (2) is reduced to a conventional VAR model in first differences if the rank $(r)$ of the $(m \times m)$ matrix $\Pi$ is zero. On the other hand, if $\Pi$ has rank $r=m$, all the time series variables in $Y_{t}$ are stationary. Of the most importance is when $0<r<m$, suggesting $r$ cointegrating vectors exist. Thus, there must exist: 
Ho et al., Assessing the Dynamic Relationship Between Small and Large Cap Stock Prices

$$
\Pi=\alpha \beta^{\prime}
$$

where $\alpha$ and $\beta$ are ( $m \times r)$ matrices both of rank $r$. Substituting (3) into (2) yields the cointegrated VAR model:

$$
\Delta Y_{t}=\mu+\sum \Gamma_{i} \Delta Y_{t-i}+\alpha\left(\beta^{\prime} Y_{t-k}\right)+\varepsilon_{t}
$$

The columns of the matrix $\alpha$ are speed of adjustment parameters. If $\alpha_{i}$ is larger, the response of the $i^{\text {th }}$ variable to the previous period's deviation from the long-run equilibrium level is greater. The rows of the matrix $\beta$ are the cointegrating vectors of particular interest in this study. It holds that the linear combination $\beta^{\prime} y_{t}$ is stationary even though the vector $Y_{t}$ is comprised of variables that are nonstationary. To interpret the cointegrating vector with respect to the $i^{\text {th }}$ variable, the cointegrating vector $\beta$ can be normalized by dividing each coefficient of $\beta$ by $\beta_{i}$. Each cointegrating vector in this study is normalized with respect to the log of the small cap portfolio, which is the variable of interest.

In this study, we are working with a 4 -dimensional VAR process of the $2^{\text {nd }}$ order. $Y_{t}$ is the $(4 \mathrm{x} 1)$ random vector $\left(\right.$ small $\left._{t}, \operatorname{large}_{t}, i p_{t}, r_{t}\right)$, namely, small cap stock prices, large cap stock prices, industrial production, and 3-month Treasury bill rates.

Using both the maximum eigenvalue and the trace test statistic for reduced rank, hypothesis tests are conducted with the null hypothesis that the number of cointegrating vectors is at most $r(r=0,1, \ldots, m)$ as outlined in Johansen $(1991,1995)$. The cointegration tests are conducted assuming the presence of a constant in the cointegrating equation (with no trend) but not in the VAR. Since stock prices typically don't exhibit trends, a trend term was deemed inappropriate for the VECM. To provide robustness to this study, hypothesis tests are conducted for no cointegrating vectors and at most one cointegrating vector for each recursive sample and each ten year rolling sample. The existence of only one cointegrating vector $(r=1)$ for the full sample, forward recursive samples, and ten year rolling samples strongly suggests that one long-run equilibrium level exists between small cap stock prices, large cap stock prices, industrial production, and 3month Treasury bill rates.

\section{EMPIRICAL ANALYSIS}

\subsection{Data Description}

This study uses monthly stock market data from the Center for Research in Security Prices (CRSP) available from 1926 to 2006. The macroeconomic variables in this study consist of seasonally adjusted industrial production, which was gathered from the Global Insight website, and 3-month Treasury bill rates, also provided by the CRSP. Seasonally adjusted industrial production data is used since we are not investigating any seasonal effects in this study. All data is presented in natural logarithms so that coefficients can be interpreted relative to the dependent variable as elasticity.

The CRSP capitalization-based data ranks the stocks listed on the NYSE, the AMEX, and the Nasdaq by market capitalization and then splits them into ten equally populated deciles or portfolios. Specifically, the top two deciles (the top 20 percent of all firms measured in market capitalization) contain large cap stocks, deciles 3 through 5 contain mid cap stocks, deciles 6 through 8 contain small cap stocks, and the last two deciles (the smallest 20 percent) contain micro caps. To account for changing market capitalization sizes over time, the CRSP rebalances each of the deciles every quarter based on each stock's price and number of shares outstanding from the previous quarter. The data set is a monthly series ranging from the start of 1926 to the end of 2006. For the small cap stocks, we use CRSP portfolios nine and ten combined, which covers the entire micro cap universe, and for the large cap stocks we use CRSP portfolios one and two combined, which covers the majority of the S\&P 500.

Table 1: Average Monthly Returns from 1926-2006

\begin{tabular}{|c|c|c|c|c|}
\hline $\begin{array}{c}\text { Portfolio } \\
\text { Decile }\end{array}$ & $\begin{array}{c}\text { Monthly Average } \\
\text { Total Return }\end{array}$ & $\begin{array}{c}\text { Monthly } \\
\text { Risk }^{*}\end{array}$ & $\begin{array}{c}\text { Monthly Average } \\
\text { Capital Return }\end{array}$ & $\begin{array}{c}\text { Monthly Average } \\
\text { Income Return }\end{array}$ \\
\hline Largest & $0.90 \%$ & $5.10 \%$ & $0.57 \%$ & $0.33 \%$ \\
\hline 2 & $1.04 \%$ & $5.91 \%$ & $0.70 \%$ & $0.34 \%$ \\
\hline 3 & $1.10 \%$ & $6.39 \%$ & $0.77 \%$ & $0.33 \%$ \\
\hline 4 & $1.11 \%$ & $6.68 \%$ & $0.79 \%$ & $0.32 \%$ \\
\hline 5 & $1.16 \%$ & $6.99 \%$ & $0.85 \%$ & $0.32 \%$ \\
\hline 6 & $1.20 \%$ & $7.34 \%$ & $0.88 \%$ & $0.31 \%$ \\
\hline 7 & $1.22 \%$ & $7.89 \%$ & $0.93 \%$ & $0.29 \%$ \\
\hline 8 & $1.28 \%$ & $8.57 \%$ & $1.02 \%$ & $0.26 \%$ \\
\hline 9 & $1.34 \%$ & $9.20 \%$ & $1.12 \%$ & $0.22 \%$ \\
\hline Smallest & $1.57 \%$ & $10.74 \%$ & $1.42 \%$ & $0.15 \%$ \\
\hline
\end{tabular}


Table 1 displays the descriptive statistics for the portfolios constructed by the CRSP. Consistent with our previous studies, the table shows how average monthly total returns increase as market capitalization decreases. In the extreme case, the tenth decile returns on average is $1.57 \%$ per month while the first decile on average returns only $0.90 \%$ per month. A similar trend is easily noticeable for average monthly capital appreciation returns. The tenth decile returns nearly three times as much in capital appreciation per month $(1.42 \%)$ as compared to the first decile $(0.57 \%)$. On the other hand, dividend returns tend to be higher for large capitalization stocks. The first decile returns on average $0.33 \%$ per month from dividends while the tenth decile returns on average only $0.15 \%$ per month. The trends in capital and dividend returns can be attributable to the scale at which the firms operate. Assuming small firms have less market penetration than large firms, small firms are more likely to retain profits to expand their market share instead of returning the profits to the investors through dividends. Also, monthly risk exhibits an expected trend, increasing as the market capitalization decreases. Higher short-term risk is more likely for small cap stocks due to factors such as liquidity issues, lack of information and research available to the average investor, transaction costs, and investor psychology or hysteria. The cyclical nature of the size effect can also be presented by graphs (available upon request), which shows that sometimes small caps outperform substantially, while other times they outperform only slightly. On average though, it seems that when small caps outperform, they outperform with a larger magnitude than when large caps outperform.

We have conducted the ADF unit-root tests, and the results show that all the four time series contain a single unit root in levels and are stationary with the first difference. Therefore, we can proceed in levels since each series is integrated of the first order, setting the stage for the potential existence of a stationary linear combination between the variables.

\subsection{Empirical Results}

We began by choosing the order $(k)$ of the VAR. The lag lengths were determined by the AIC and the SBC and were set at two lags. Residual diagnostic tests were performed as well and show no residual autocorrelation. Thus, the use of two lag lengths ensures that the error terms are uncorrelated. Also,

\begin{tabular}{|c|c|c|c|c|}
\hline Hypothesized Rank ( $r)$ & Eigenvalue & Likelihood Ratio & $5 \%$ Critical Value & Probability \\
\hline \multicolumn{5}{|c|}{ Trace Statistic for Cointegrating Rank } \\
\hline$r=0^{\star \star}$ & 0.184332 & $98.41748^{* *}$ & 54.07904 & 0.0000 \\
\hline$r \leq 1$ & 0.055046 & 32.19948 & 35.19275 & 0.1016 \\
\hline$r \leq 2$ & 0.030145 & 13.79845 & 20.26184 & 0.3035 \\
\hline \multicolumn{5}{|c|}{ Maximum Eigenvalue Statistic for Cointegrating Rank } \\
\hline$r=0^{\star \star}$ & 0.184332 & $66.21801^{* *}$ & 28.58808 & 0.0000 \\
\hline$r \leq 1$ & 0.055046 & 18.40103 & 22.29962 & 0.1605 \\
\hline$r \leq 2$ & 0.030145 & 9.94783 & 15.89210 & 0.3391 \\
\hline \multicolumn{5}{|c|}{ Normalized Cointegrating Vector } \\
\hline & LLargeCap & LIndProduction & LRiskFree & C \\
\hline LSmallCap & $-1.920238^{* *}$ & $11.87975^{* *}$ & -0.135791 & $-45.2417^{* *}$ \\
\hline Standard Error & 0.36939 & 1.60145 & 0.17244 & 6.05741 \\
\hline t-statistic & -5.19840 & 7.41812 & -0.78746 & -7.46882 \\
\hline
\end{tabular}
since stock prices typically do not have a trend, test statistics for the VECM are calculated allowing for the presence of a constant in the cointegrating equation (with no trend) but not in the VAR. Table 2 reports the cointegration test results for the full sample from 1980 to 2006, suggesting the existence of at least one cointegrating vector between small cap stock prices, large cap stock prices, industrial production, and 3-month Treasury bill rates.

At the bottom of Table 2, the cointegrating vector is presented normalized with respect to small cap stock prices. Standard errors and t-statistics are presented as well. It is easy to see that large cap stock prices and industrial production have highly significant relationships with small cap stock prices as expected. The significant negative relationship between small and large cap stock prices supports the theory that the size effect is cyclical even after controlling for macroeconomic conditions. The significant and positive relationship estimated for industrial production is also consistent with theory. Greater economic activity measured as industrial production ultimately leads to a rising stock market through increased cash flows and the anticipation of increased future dividends. Finally, the negative relationship estimated for interest rates is consistent with theory, but it is insignificant. Higher interest rates lead to a substitution of stocks into riskfree interest bearing assets (see Farrell, 1985). The insignificance of interest rates may be due to the high inflation rates from the early 1980s. The expected inflation rate most likely remained very high after several years of stagflation in the 1970s. Even though interest rates declined considerably, there may have not been much substitution into stocks as predicted by the dividend discount model (DDM), yielding an insignificant estimation for the interest rate coefficient. 
Cholesky Variance Decomposition: In order to estimate the Cholesky variance decomposition, we must consider the ordering of the variables in the VAR. Stock prices typically anticipate the behavior of other variables because stocks are priced on future expectations. For example, stock prices typically price in past information as well as estimates on the future, acting as a barometer for the general economy. Thus, the two sets of stock prices are put first, followed by industrial production and interest rates. Also, since Kanas and Kouretas (2005) contend there is a lead-lag effect between large and small cap stock prices, large cap stock prices will be placed first since small cap stock prices tend to react to them. Table 3 presents the Cholesky variance decomposition of both small and large cap stock prices. The results suggest that large cap prices play the largest role in the decomposition of small cap price variance. Past developments in large cap prices explain $63.88 \%$ of the variance of small cap price forecasts. Small cap prices explain $26.49 \%$ of the variation in themselves. As a comparison to the latter statement, large cap prices explain $91.32 \%$ of the variation in themselves while small cap prices only explain $0.09 \%$. Clearly, large cap prices have a larger impact on small cap prices while the reverse is weaker.

Table 3: Variance Decomposition after 60 Months (5 Years) in Percent

\begin{tabular}{lcccc}
\hline Cholesky Ordering & LLargeCap & LSmallCap & LIP & L3M T-Bill \\
\hline Decomposition of LLarge Cap & 91.32 & 0.09 & 5.52 & 3.07 \\
\hline Cholesky Ordering & LLargeCap & LSmallCap & LIP & L3M T-Bill \\
\hline Decomposition of LSmall Cap & 63.88 & 26.49 & 4.03 & 5.60 \\
\hline
\end{tabular}

Cholesky Impulse Responses: The restricted VECM can be evaluated using standard Cholesky impulse responses since the Cholesky estimation orthogonalizes the innovations. The impulse responses allow the effects of an individual random shock to build up over time through the lagged value of the dependent variable in the VECM. Also, the impact of the random shock builds up through current and lagged effects from changes in the first variable on the other variables. Figure 1 displays the Cholesky impulse responses for large cap stock prices, industrial production, and the 3-month Treasury bill rates with respect to small cap stock prices five years out.

Since all the variables are integrated of order one, it is expected that a shock does not dissipate over time. Instead, it is expected to stabilize at some point. As expected, large cap stock prices have a positive and persistent impact on small cap stock prices. The impact of a one standard deviation positive large cap price shock on small cap prices builds up slowly before reaching a stable level. The stability of the shock means the shock persists in the long-run. Both industrial production and the 3-month Treasury bill rate have a negative impact on small cap stock prices. They both initially decrease before stabilizing in the long-run. Also, impulse responses were explored for several sub-periods of the overall sample. Each is very similar to the overall results presented in Figure 1. Only the magnitudes vary.

We have conducted cointegration robustness Exercises for the forward recursive and the ten year rolling samples, and the parameter stability tests for each of the forward recursive and ten year rolling samples. The results are available upon request. Based on the cointegration tests, parameter instability does not appear to be a glaring problem. Hence, after considering time variation within the study period, it is likely one long-run equilibrium level exists between small cap stock prices, large cap stock prices, industrial production, and interest rates.

\section{CONCLUDING REMARKS}

In this study we have employed a vector error correction model framework with US stock market data from 1980 to 2006 to investigate the long-run relationship between small and large cap stock prices. After conducting robustness tests on forward recursive and ten

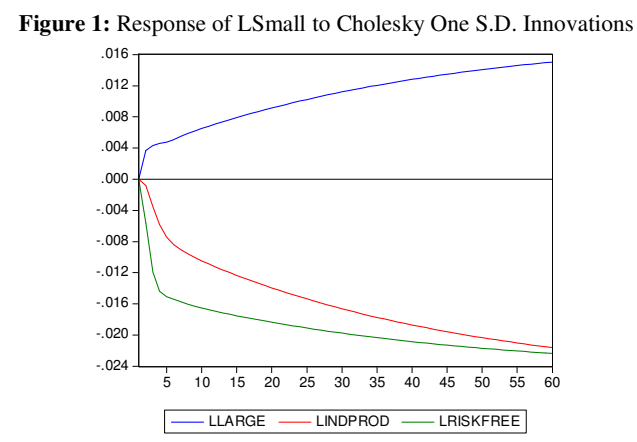


year rolling samples, we find evidence of one long-run cointegrating vector. Of more importance, there is a consistently negative and highly significant relationship between small and large cap stock prices. The results hold even after controlling for the macroeconomic climate through the inclusion of industrial production and the 3-month Treasury bill rate as independent variables. This could suggest that the size effect exhibits a cyclical pattern. Our analysis also provides supporting evidence that the size effect appears to exhibit predictable reversals when considering long investment horizons.

The results suggest that small cap stocks can be considered less risky than large cap stocks over long holding periods, hence small cap stocks appear to be good long-run investments relative to large cap stocks. Small cap stocks relative to large cap stocks seem to be excellent investments provided the investor is willing to buy and hold them. In the extreme long-run, it is likely the investor will realize phenomenal gains, and in the end, the size effect and the case for managing market capitalization appears alive and well.

The results have important investment implications. Since small and large cap stock prices seem to exhibit a negative long-run relationship, the proposed cyclical nature of the size effect appears to be a real phenomenon. Most academics and investors have claimed that the size effect is dead, believing that abnormal returns due to differing market capitalizations no longer exist. This study presents a compelling case that the size effect still exists. Further research could enhance the results put forth in this paper. For example, it would be interesting to see if cointegrating relationships exist between any of the other CRSP marketcapitalization sorted portfolios. The existence of a long-run relationship between mid caps and large caps or mid caps and small caps could enhance our understanding of the cyclical nature of the size effect. Also, the inclusion of other macroeconomic variables could help explain the cyclicality.

\section{REFERENCES}

Banz, Rolf W. (1981), "The Relationship between Return and Market Value of Common Stock," Journal of Financial Economics, 9, 3-18.

Daniel, Kent and Sheridan Titman (1997), "Evidence on the Characteristics of Cross-Sectional Variation in Stock Reutrns," Journal of Finance, 52, 1-33.

Dichev, Ilia D. (1998), “Is the Risk of Bankruptcy a Systematic Risk?” Journal of Finance, 53, 1131-1147.

Engle, Robert F. and Clive W. Granger (1987), "Cointegration and Error Correction: Representation, Estimation, and Testing," Econometrica, 55, 251-276.

Fama, Eugene F. (1981), "Stock Returns, Real Activity, Inflation and Money," American Economic Review, $71,545-565$.

Fama, Eugene F. and Kenneth R. French (1988), "Permanent and Temporary Components of Stock Prices," Journal of Political Economy, 96, 246-273.

Fama, Eugene F. and Kenneth R. French (1992), "The Cross-Section of Expected Stock Returns," The Journal of Finance, 47, 427-465.

Farrell, James L. Jr. (1985), “The Dividend Discount Model: A Primer,” Financial Analysts Journal, 41, 1619.

Gustafson, Kenneth E., and James D. Miller (1999), “Where has the Small-Stock Premium Gone?” Jounral of Investing, 8, 45-55.

Hansen, Henrik and Soren Johansen (1999), "Some Tests for Parameter Constancy in the Cointegrating VAR,” Econometrics Journal, 2, 25-52.

Johansen, Soren (1991), "Estimation and Hypothesis Testing of Cointegration Vectors in Gaussian Vector Autoregressive Models," Econometrica, 59, 1551-1580.

Johansen, Soren. Likelihood-based Inference in Cointegrated Vector Autoregressive Models. Oxford: Oxford University Press, 1995.

Kanas, Angelos and Georgios P. Kouretas (2005), "A Cointegration Approach to the Lead-Lag Effect among Size-Sorted Equity Portfolios," International Review of Economics \& Finance, 14, 181-201.

Reinganum, Marc R. (1992), "A Revival of the Small-Firm Effect," Journal of Portfolio Management, 18, 55-62.

Reinganum, Marc R. (1999), “The Significance of Market Capitalization in Portfolio Management Over Time," Journal of Portfolio Management, 25, 39-49.

Van Dijk, Mathijs A. (2007), "Is Size Dead? A Review of the Size Effect in Equity Returns," Working Paper Series, RSM Erasmus University-Department of Financial Management. 